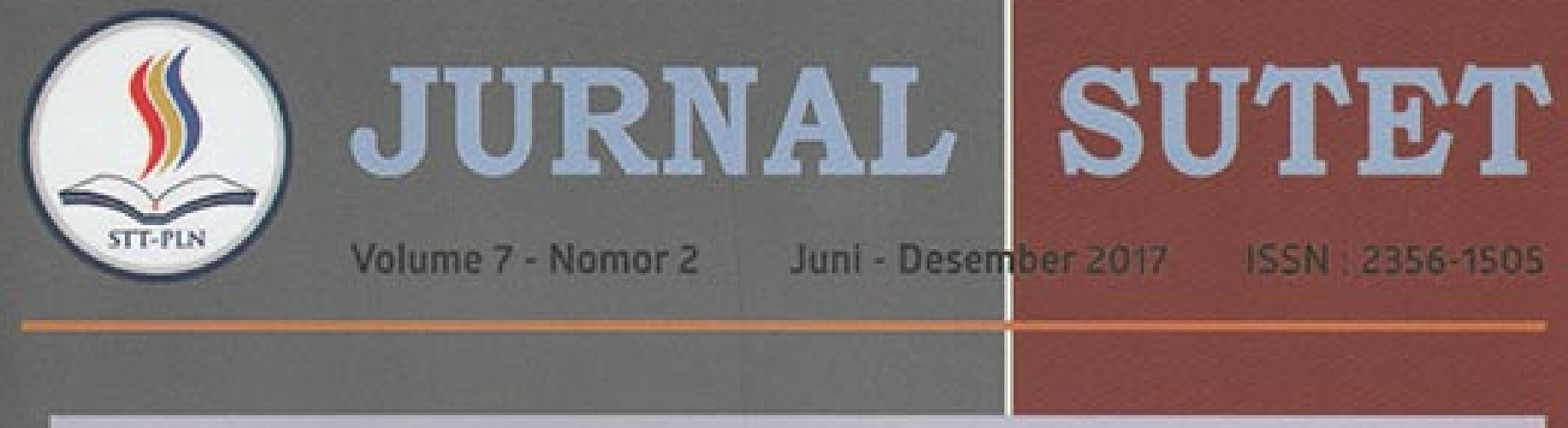

PENGARUH RUGI-RUGI SALURAN PADA JARINGAN TRANSMISI TEGANGAN MENENGAH PENYULANG E2 GARDU INDUK EMBALUT TENGGARONG

Juara Mangapul Tombunan: DjokoSusanto; Rima Isyana Restuwangi

\title{
FIRE SENSING SYSTEM
}

Aas Wasri Hasanah; Rinna Horiyat; Oktario Handayani

\section{PERANCANGAN RANGKAIAN PENGUAT DAYA DENGAN TRANSISTOR}

Tosdik Darmana, Tony Koerniawan

STUDI PERAMALAN BEBAN RATA-RATA JANGKA PENDEK MENGGUNAKAN METODA AUTOREGRESSIVE INTEGRATED MOVING AVERAGE (ARIMA)

Adri Senen: Titi Ratnasari

PERANCANGAN SISTEM KONTROL GLYCOL REGENERATION UNIT DENGAN DCS DeItaV

DI ONSHORE GAS PLANT

Muhamad Syahrudin: Rummi Santi Rama Sirait

RANCANG BANGUN RUANG PINTAR MINIMALIS TENAGA SURYA DENGAN SISTEM KONTROL BERBASIS ARDUINO

Dwi Anggraini; Miftohul Fikri; Hendrianto Husada

\section{PERANCANGAN KENDALI GARASI RUMAH BERBASIS WEB VIA WIRELESS LAN}

Akhmad Syahroni; Eka Purwa Laksano; Nifty Foth

ANALISA PROTEKSI HILANG EKSITASI PADA GENERATOR SINKRON DI PLTGU MUARA TAWAR GT UNIT 1.3

Ibnu Hajor: Usman Fadillah

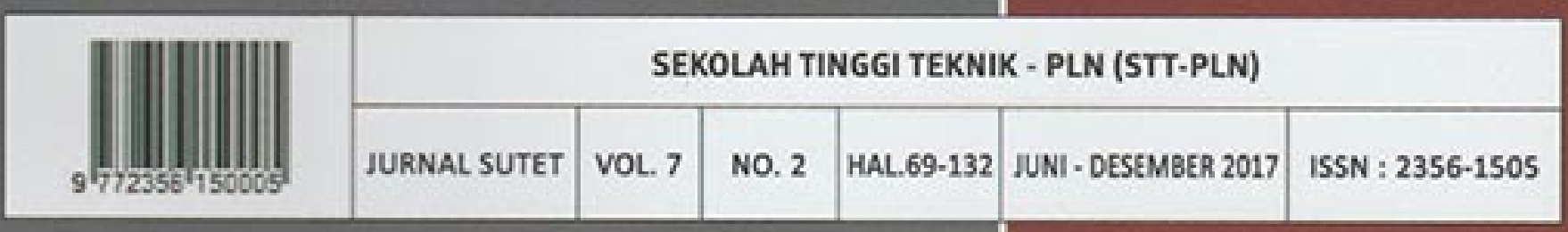




\title{
PERANCANGAN SISTEM KONTROL GL YCOL REGENERATION UNIT DENGAN DCS DeltaV DI ONSHORE GAS PLANT
}

\author{
Muhamad Syahrudin ${ }^{1}$, Rummi Santi Rama Sirait ${ }^{2}$ \\ 1,2 Jurusan Teknik Elektro, Fakultas Teknik, Universitas Budi Luhur \\ e-mail : rummi.sirait@budiluhur.ac.id
}

\begin{abstract}
The glycol regeneration process is an integrated part of the glycol dehydration unit (GDU) system. Each plant has a customized configuration to the needs of the process, for the case in this onshore field because the gas produced from the well is good enough with a fairly low water content, then does not use Glycol Contactor. Instead used low temperature separator and glycol generation unit. DCS DeltaV is used to operate, documentation and optimization of gas processes. By using oscillation method and closed loop system obtained PID tuning result with parameter $P=387, I=57$ and $D=53$. The response of the control system is conditioned overshoot from its setpoint to accelerate the rise of the temperature plant. When the temperature of glycol regeneration is at $262^{\circ} \mathrm{F}$, the alarm will light Hi limit and Hi Hi limit at $290^{\circ} \mathrm{F}$, while at $245^{\circ} \mathrm{F}$ the alarm will light low limit and Low Low limit at temperature $0^{\circ} \mathrm{F}$.
\end{abstract}

Keywords : Glycol Dehydration Unit, DCS, PID

Abstrak : Proses glycol regeneration merupakan bagian yang terintegrasi dari sistem glycol dehydration unit (GDU). Setiap plant memiliki konfigurasi yang disesuaikan dengan kebutuhan proses, untuk kasus di lapangan onshore ini karena gas yang dihasilkan dari sumur sudah cukup baik dengan kandungan air yang cukup rendah, maka tidak menggunakan Glycol Contactor. Sebagai gantinya digunakan low temperature separator dan glycol generation unit. DCS DeltaV digunakan untuk mengoperasikan, dokumentasi dan optimalisasi proses gas. Dengan menggunakan metode osilasi dan sistem loop tertutup diperoleh hasil tuning PID dengan parameter $P=387, I=57$ dan $D=53$. Respons sistem kontrol dikondisikan overshoot dari setpoin-nya untuk mempercepat kenaikan temperature plant. Pada saat temperatur glycol regeneration berada pada titik kerja $262^{\circ}$ $F$, alarm akan menyala Hi limit dan Hi Hi limit pada temperatur $290^{\circ} \mathrm{F}$, sedangkan pada temperature $245^{\circ} \mathrm{F}$ alarm akan menyala low limit dan Low Low limit pada temperature $0^{\circ}$ $F$.

Kata kunci : Glycol Dehydration Unit, DCS, PID

\section{PENDAHULUAN}

Proses pengolahan dalam industri minyak dan gas terdiri dari beberapa tahapan mulai dari sumur gas hingga siap jual dengan spesifikasi kebutuhan industri. Salah satu rangkaian proses pengolahan tersebut adalah pemisahan kandungan air dalam gas (dehydration)[1].

Dehydration Unit Plant merupakan unit kerja yang dirancang untuk memisahkan uap air yang terkandung di dalam gas [2]. Dehydration unit dibangun untuk mengolah gas supaya tidak membeku dan diharapkan hasil pengolahan gas sudah mulai mendekati spesifikasi dari sales gas.

Penelitian ini bermaksud menganalisa bagaimana cara kerja sistem pengendalian level dan suhu pada Glycol Contactor dengan Distributed Control System (DCS) dengan menggunakan software DCS DeltaV. Di samping itu kegiatan ini bertujuan untuk mengetahui secara langsung implementasi sistem kontrol di dunia industri dan mengetahui kestabilan sistem kontrol DCS. 


\section{LANDASAN TEORI}

Suatu sistem kontrol memiliki tujuan tertentu yaitu untuk mengatur keluaran (output) dengan kondisi/keadaan yang telah ditetapkan, dengan masukan (input) melalui elemen sistem kontrol, sehingga kualitas keluaran yang dihasilkan tergantung dari proses yang dilakukan oleh sistem kontrol.

Dalam aplikasi sistem kontrol digunakan beberapa perangkat sesuai kebutuhan lapangan diantaranya : Distributed Control System (DCS), Supervisory Control and Data Acquisition (SCADA), Progammable Logic Control (PLC) dan Microcontroller.

\subsection{Distributed Control System (DCS)}

Distributed Control System (DCS) merupakan suatu sistem yang mendistribusikan berbagai fungsi yang digunakan untuk mengendalikan berbagai variabel proses dan unit operasi proses menjadi suatu pengendalian yang terpusat pada suatu control room dengan berbagai fungsi pengendalian, monitoring dan optimasi [3]. Distributed control system (DCS) digunakan dalam industri untuk memonitor dan mengontrol peralatan yang tersebar dengan atau tanpa campur tangan manusia. Sebuah DCS biasanya menggunakan komputer sebagai controller dan menggunakan propietary interconections dan protokol untuk komunikasi. Modul input dan output membentuk part komponen untuk DCS, Prosesor menerima informasi dari modul input dan mengirim informasi ke modul output. Modul input menerima informasi dari instrumentasi input dalam sistem dan modul output mengirim ke instrumen output pada sistem.

DCS adalah sebuah istilah yang sangat luas yang menggambarkan sebuah solusi untuk industri yang sangat variatif, termasuk di dalamnya adalah :

- Electrical power grids dan electrical generation plants

- Environmental control systems

- Traffic signal

- Water management system

- Refining dan chemical plants

- Pharmaceutical manufacturing

\subsection{Perbedaan Antar Sistem Kontrol}

\subsubsection{Progammable Logic Control (PLC)}

Biasanya digunakan untuk menangani industri dengan pengaturan input/output digital (on-off), dan yang membutuhkan adanya logic operation. Terutama digunakan untuk mengatur suatu relay, karena bekerja secara digital (on-off). Dituntut memiliki scanning time yang cepat dengan orde 1 milisecond.

\subsubsection{Distributed Control System (DCS)}

Distributed Control System (DCS) Biasanya digunakan untuk menangani proces industri dengan parameterparameter analog sebagai input/output. Memiliki scanning time yang lebih lambat (ada yang mencapai orde second) dibanding PLC. DCS dituntut untuk memiliki kehandalan yang lebih tinggi karena fungsinya yang digunakan sebagai controller dalam proces industri yang penting [4]. Biasanya untuk menangani proses yang kompleks, ditangani dengan mengkombinasikan kedua system dimana biasanya PLC dikontrol oleh DCS. PLC menangani proses yang butuh action cepat dan biasanya digital process, sedangkan DCS mengatur keseluruhan system termasuk PLC tadi.

\subsubsection{Supervisory Control and Data Acquisition (SCADA)}

SCADA digunakan untuk dapat mengintegrasika dan mengkomunikasikan antar sistem kendali. Bukan sebagai kendali proses secara langsung. SCADA lebih berfungsi sebagai sistem monitor dan akuisisi data secara terpusat, biasanya berada di level manajemen untuk mengamati hasil proses industri.

\subsection{Sistem DCS DeltaV Glycol Dehidration Unit (GDU)}

Glycol Dehydration Unit plant di gunakan untuk proses pemurnian kandungan air dalam gas, sehingga sesuai spesifikasi yang dikehendaki. Dalam eksplorasi dari sumur, gas, air dan komponen yang tidak diperlukan lainnya secara bersamaan ikut terangkat dalam proses lifting. Tahapan proses pengkondisian diperlukan mulai dari separasi, amine proses dan Glycol 
dehydration. Proses pengkondisian ini memiliki resiko tinggi karena bekerja dengan bahan berbahaya, beracun dan suhu tinggi.

DeltaV sebagai controller digunakan untuk menjaga kelangsungan Glycol Dehydration proses. Transmitter sebagai field devicenya memberikan parameter kontrol untuk dibandingkan dengan set point.

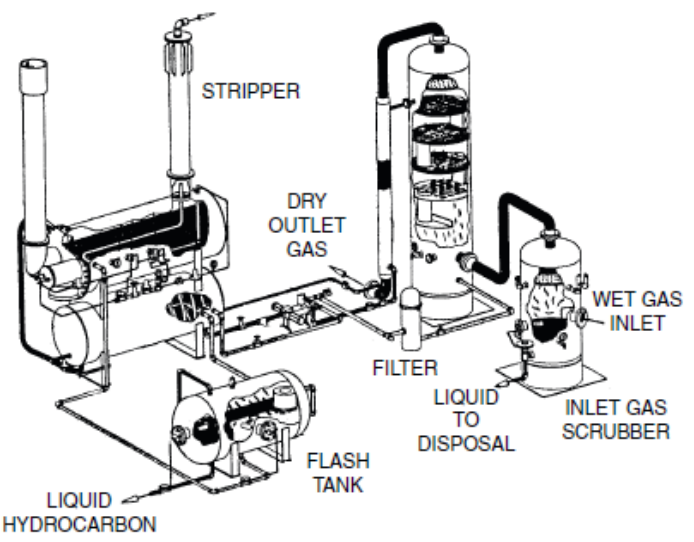

Gambar 1. Glycol Dehydration Plant.

\subsection{Transmitter Mengukur Variabel Proses}

Alat ukur (measuring device) adalah alat yang berada di lapangan untuk mengukur variable proses seperti flow, pressure, level dan temperature yang merupakan input $\mathrm{I} / \mathrm{O}$ kontroller DCS. Pada industri, proses output data dari alat ukur akan ditransmisikan ke ruangan kontrol (control room) untuk diproses lebih lanjut dalam kaitannya dengan sistem kontrol. Pemilihan jenis alat ukur yang sesuai dan terbaik untuk mengukur suatu variable proses sering kali sukar dilaksanakan, bahkan seorang engineer yang berpengalaman dan sudah mempunyai metoda pemilihan akan mengalami demikian.

Terdapat 4 terminologi penting yang biasa digunakan tentang ukuran atau pengukuran tekanan, yaitu : Absolute Pressure (tekanan absolut), Gauge Pressure (tekanan relatif), Vacum Pressure (tekanan hampa), Differential Pressure (tekanan differential).

Instrumen untuk melakukan pengukuran kuantitas aliran fluida ini disebut flowmeter. Pengembangan flowmeter ini melalui tahapan yang luas mencakup pengembangan flow sensor, interaksi sensor dan fluida melalui penggunaan teknik komputasi, transducer dan hubungannya dengan unit pemprosesan sinyal, serta penilaian dari keseluruhan sistem di bawah kondisi ideal, kondisi gangguan (disturbed), kasar (harsh), kondisi berpotensi meledak (explosive conditions) serta pada lokasi laboratorium dan lapangan. Flow transmitter di P\&ID, biasa dilambangkan dengan "FT" yang berarti Flow Transmitter. Transmiter dengan kemampuan fieldbus tidak memerlukan setting kalibrasi sinyal untuk mendaptkan output transmitter linear, dibandingkan dengan teknologi HART akan memerlukan setting zero $=0 \mathrm{~mA}$ dan $\max =20 \mathrm{~mA}$, kemudian dilakukan linearisasi bertahap $25 \%$, $50 \%$, $75 \%$ dan $100 \%$, fieldbus memerlukan kalibrasi sensor untuk memastikan data yang terkirim sesuai dengan aktual.

\section{METODE PENELITIAN}

\subsection{Pendekatan Penelitian}

Penelitian ini menggunakan bahan yang diambil dari beberapa sumber, yakni studi pustaka dengan mengumpulkan dan mempelajari literatur jurnal-jurnal ilmiah peneliti-peneliti terdahulu, buku teks, internet, dan tesis-tesis terdahulu yang berkaitan dengan sistem pengendalian level dan suhu pada Glycol Contactor dengan Distributed Control System (DCS) dengan menggunakan software DCS DeltaV.

\subsection{Alat Penelitian}

Alat yang digunakan untuk penelitian ini antara lain :

a) Aplikasi Matlab versi 2012b untuk simulasi hasil penelitian

b) Komputer Personal (PC) dan computer Mobile (Laptop) yang dilengkapi oleh program :

- Microsoft Word 2007, digunakan untuk menulis hasil laporan.

- Microsoft Excel 2007, digunakan untuk menyusun data hasil penelitian dalam bentuk tabel.

- Mirosoft Visio 2007, digunakan untuk membuat gambar 


\subsection{Diagram Alir Penelitian}

Diagram alir penelitian ditunjukkan pada gambar 2 .

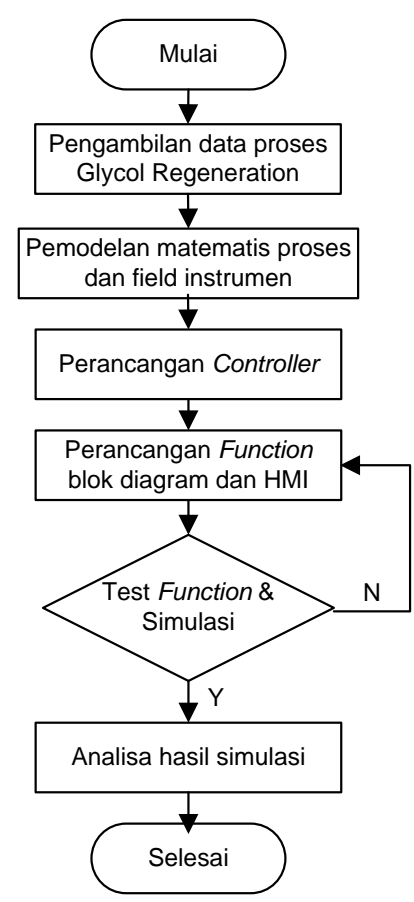

Gambar 2. Diagram alir penelitian

\subsection{Perancangan Kontrol Glycol Regeneration Unit dengan DCS DeltaV}

Proses regenerasi glycol merupakan bagian yang terintegrasi dari sistem glycol dehydration unit (GDU). Setiap plant memiliki konfigurasi yang disesuaikan dengan kebutuhan proses [4], untuk kasus di lapangan onshore ini, karena gas yang dihasilkan dari sumur sudah cukup baik dengan kandungan air yang cukup rendah, maka tidak menggunakan Glycol Contactor. Sebagai gantinya digunakan low temperature separator dan glycol reboiler.

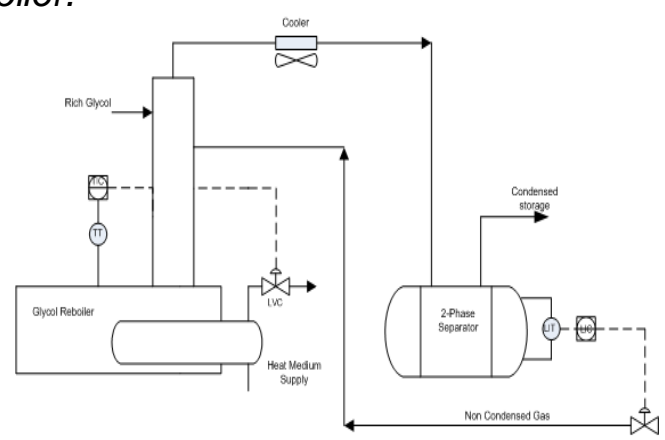

Gambar 3. Glycol regeneration unit Package

Kolom distilasi pada sistem glycol reboiler mempertemukan cairan rich glycol dengan gas non-kondensat dari separator 2 phasa. Untuk menghasilkan produk sesuai spesifikasi yang dikehendaki, maka keduanya separator 2-phasa dan reboiler harus dikontrol. Pengontrolan temperatur fluida output yang menjadi nilai proses value $(P V)$ sistem kontrol dilakukan dengan cara mengontrol bukaan valve (sebagai penggerak) yang terhubung dengan sistem glycol reboiler. Semakin besar sinyal kontrol yang berasal dari modul temperatur TIC (temperature indicator controller) aliran dari panas dari heat medium yang dillewatkan akan semakin besar (bukaan valve semakin besar) dan sebaliknya, semakim kecil (bukaan valve semakin menutup). Besar kecilnya aliran fluida dari heat medium akan mempengaruhi temperatur rich glycol di regeneration package.

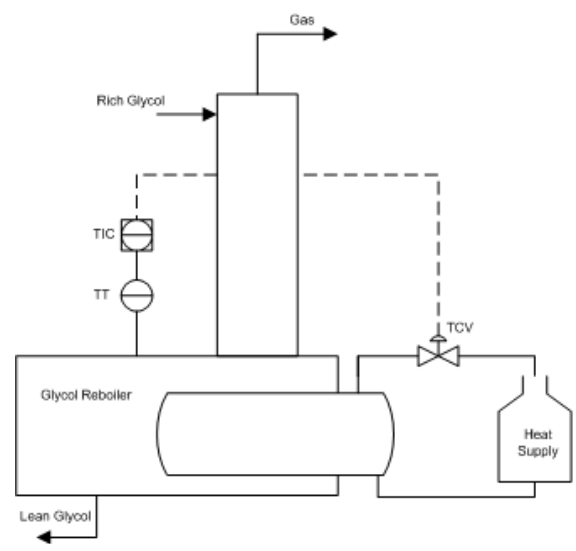

Gambar 4. Glycol Reboiler Blok

Reboiler dikontrol dengan menggunakan heat input kontrol, dengan demikian laju panas/heat yang diberikan ke sistem reboiler akan terkontrol [5]. Dengan menggunakan hukum kesetimbangan energi disekitar daerah kerjanya, maka model matematis antara output proses (deviasi temperatur output) terhadap perubahan input yang terjadi dalam proses tersebut dapat dicari dengan persamaan 1 (asumsikan dalam kondisi ideal, heat exchanger tersebut terisolasi penuh dengan lingkungan).

$\frac{d}{d t}\left(V \rho C Q_{T}(t)\right)=C w \theta_{\text {in }}-w C \theta_{T}+h_{\text {in }}$

dimana :

$V \quad=$ volume tangki (konstan) dalam $\mathrm{m}^{3}$ 
$w$ =laju aliran fluida dalam keadaan steady dalam $\mathrm{kg} /$ menit

$\rho=$ densitas fluida (konstan) dalam $\mathrm{kg} / \mathrm{m}^{3}$

$\mathrm{C}=$ kalor jenis fluida dalam $\mathrm{J} / \mathrm{kg}$.

$\theta_{\text {in }}=$ Perubahan temperature fluida input di sekitar nilai steady awalnya $\left({ }^{0} \mathrm{C}\right)$

$\theta_{T}=$ Perubahan temperature fluida dalam tangki di sekitar nilai steady awalnya $\left({ }^{\circ} \mathrm{C}\right)$

$h_{\text {in }}=$ Perubahan laju kalor masukan di sekitar nilai steady awalnya (J/menit)

Dari data dilapangan didapatkan parameter karakteristik plant sebagai berikut :

- Aliran rich glycol ke dalam plant sebesar $4314,3 \mathrm{lb}_{\mathrm{m}}$ pure TEG/hr

- Aliran lean glycol ke dalam plant sebesar $3406,3 \mathrm{lb}_{\mathrm{m}}$ pure TEG/hr

- Kalor jenis glycol (TEG) $=0.62$

- Temperatur lean hi limit Glycol setpoint plant $390^{\circ} \mathrm{F}$ dan temperatur out reboiler $374^{\circ} \mathrm{F}$.

- Temperatur input rich glycol: $90^{\circ} \mathrm{F}$

Temperatur kerja glycol regen di tentukan dengan persamaan (2).

$$
Q=m_{\text {lean }} C_{p} \Delta T
$$

Sehingga:

$Q=\left(3406,3 \cdot \frac{l b_{m} T E G}{\text { hour }}\right)\left(0.64 \frac{b t u}{l b_{m}{ }^{o} F}\right)(390-$ 190) (3)

$Q=436.000 \mathrm{Btu} / \mathrm{hr}$

Selanjutnya nilai $\mathrm{T}$ dapat ditentukan dari persamaan 2 dan nilai $Q$ pada persamaan 4 .

$$
\begin{aligned}
& 436.000=m_{\text {rich }} C_{p}(T-90) \\
& 436.000=(4314,3)(0.62)(T-90) \\
& T=253^{\circ} \mathrm{F} \quad \ldots \ldots \ldots \ldots \ldots \ldots \ldots \ldots \ldots \ldots \ldots \ldots \ldots \ldots \ldots \ldots \ldots \ldots \ldots \ldots
\end{aligned}
$$

Untuk pendekatan sistem orde 1 fungsi dari plant glycol regen sebagai berikut :

$\frac{Q_{0}}{Q_{i}}(s)=\frac{K_{Q T}}{\tau_{Q T} S+1}$

$K_{Q T}=\frac{\text { Span_output }}{\text { Span_input }}=\left(\frac{390-374}{20-4}\right)=1 \ldots$.

Dengan time konstant plant selama 40 menit, maka persamaan menjadi :
$\frac{Q_{0}}{Q_{i}}(s)=\frac{1}{40 S+1}$

\subsubsection{Perancangan Temperatur Transmitter}

Dalam perancangan ini digunakan thermocouple tipe $\mathrm{J}$ untuk sensor transmitter, dengan jangkauan operasi 0 $400^{\circ} \mathrm{F}$ dengan nilai set point $253^{\circ} \mathrm{F}$, blok perancangan ditunjukkan Gambar 5.

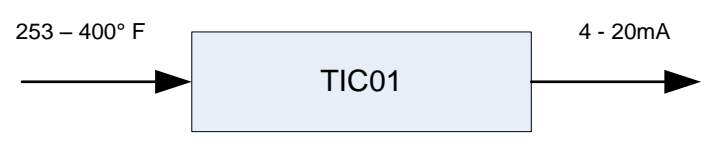

Gambar 5. Blok persamman sistem transmitter

Untuk pendekatan sistem orde 1 fungsi dari termocouple sebagai berikut :

$\frac{T_{0}}{T_{i}}(s)=\frac{K_{T T}}{\tau_{T T} S+1}$

Dengan nilai $\mathrm{K}$ sebagai perbandingan transmitter temperature pada persamaan 10.

$K_{T T}=\frac{\text { Span_output }}{\text { Span_input }}$

Besarnya time konstan dengan temperatur kerja termocouple $\tau_{T T}$ adalah 40 menit, sehingga persamaan transfer fungsi level transmitter seperti persamaan 11.

$\frac{T_{0}}{T i}(s)=\frac{0,1}{40 S+1}$

\subsubsection{Kontrol Valve}

Bagan persamaan sistem kontrol valve ditunjukkan pada gambar 6 .

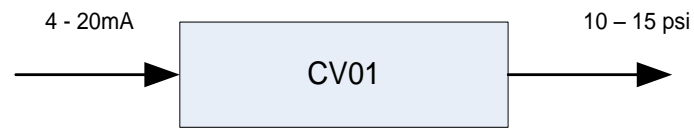

Gambar 6. Bagan persamaan sistem kontrol valve

Fungsi transfer untuk kontrol valve juga didapat dengan pendekatan sistem orde 1:

$\frac{C V_{0}}{C V_{i}}(s)=\frac{G_{C V}}{\tau_{C V}+1}$

$G_{C V}=\frac{\text { Span_output }}{\text { Span_input }}=\frac{5}{16}=0.3 \mathrm{psi} / \mathrm{mA}$ 
Besarnya time konstan $\tau_{C T}$ adalah 1 menit, sehingga persamaan transfer fungsi level transmitter menjadi :

$\frac{C V_{0}}{C V_{i}}(s)=\frac{0.3}{1 s+1}$

\section{HASIL DAN PEMBAHASAN}

Dengan menggunakan persamaan 13 dan 14, proses dapat di simulasikan dengan bantuan aplikasi Matlab, dalam simulasi ini menggunakan Matlab versi 2012b. Gambar simulasi ditunjukkan gambar 7 .

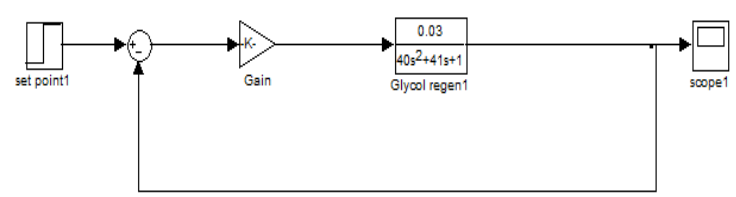

Gambar 7. Simulasi persamaan sistem dengan matlab.

Gambar 8 adalah output dari scope dari plant yang disimulasikan dengan input step sebelum diberikan tuning gain proposional, interal maupun derivatif.

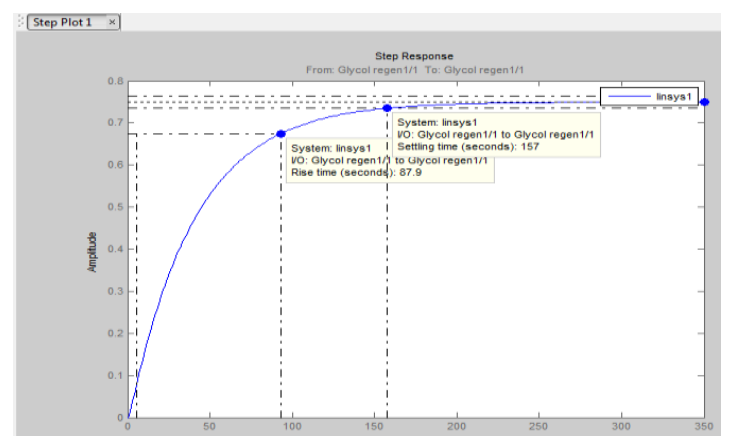

Gambar 8. Grafik Kontrol Glycol regeneration

Hasil simulasi dengan Matlab linear analysis di dapatkan masing-masing parameter seperti pada tabel 1.

Tabel 1. Transient parameter

\begin{tabular}{|l|l|}
\hline Rise time & $87,9 \mathrm{sec}$ \\
\hline Setting time & $157 \mathrm{sec}$ \\
\hline Peak respond & $0.75 \mathrm{sec}$ \\
\hline Steady state / amp & 0.748 \\
\hline
\end{tabular}

Respon kontrol proporsional dalam menangggapi perubahan setpoin atau gangguan (distrubance) akan menunjukkan offset (error steady) pada output proses yang dikontrolnya. Besar kecilnya error steady sangat tergantung pada nilai penguatan (gain) yang dipilih. Semakin besar penguatan proporsional yang digunakan, maka error steady akan semakin kecil. Pembesaran nilai gain tersebut selain akan memperkecil error steady, juga akan mempercepat respon output (memperkecil waktu penetapan proses), akan tetapi penambahan gain proprosional tidak dapat dilakukan secara terus menerus karena pada penguatan tertentu output proses akan menjadi kurang stabil dan sinyal mengalami osilasi.

\subsection{Tuning Parameter PID}

Meskipun nilai-nilai parameter kontrol PID besarnya dapat diatur secara independen, tetapi pengaturan atau tuning yang dilakukan terhadap salah satu parameter kontrol akan memerlukan pengaturan ulang pada parameter yang lain.

Simulasi dengan matlab untuk sistem setelah mendapat tuning dari masingmasing parmeter $\mathrm{P}, \mathrm{I}$ dan $\mathrm{D}$.

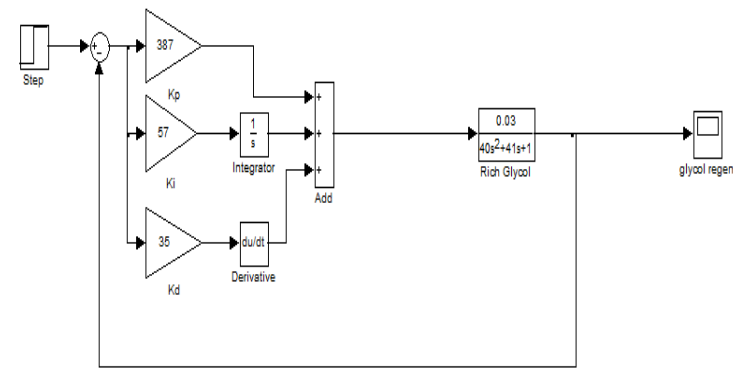

Gambar 9. Tuning PID Sistem Kontrol

Dengan metode tuning osilasi maka didapatkan masing-masing parameter PID yaitu $P=378, I=57$ dan $D=35$, setpoin temperatur yang dicapai sesuai kebutuhan plant adalah $253^{\circ} \mathrm{F}$, temperatur tersebut merupakan titik kerja dari glycol regeneration unit.

Pada prakteknya sistem DeltaV dapat mencapai titik optimal parameter PID secara otomatis dengan menggerakkan positioner transmitter secara berulang, dengan catatan kondisi plant glycol regeneration harus stabil, sebaliknya jika terjadi distrurbance, tuning parameter PID sulit mendapatkan nilai optimalnya. Gambar 10 merupakan parameter PID yang di set pada sistem. 


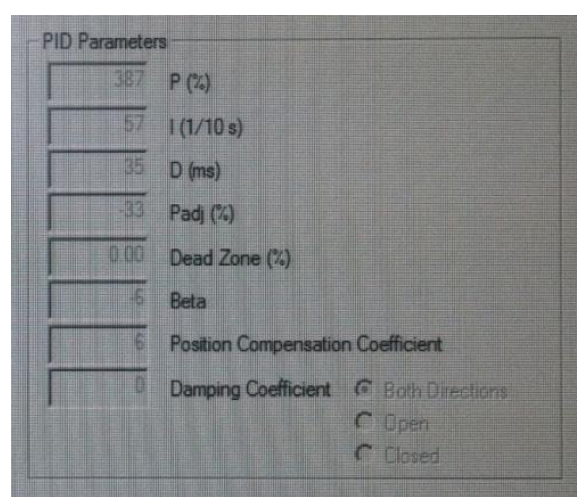

Gambar 10. PID Parameter sistem

Supaya tidak dilakukan tuning berulang untuk setiap perubahan beban yang relatif besar, sistem dapat dijadwalkan besarnya parameter PID untuk setiap besar laju produksi yang berbeda. Jika kontroler yang digunakan memiliki gain scheduling, penjadwalan tersebut pada dasarnya dapat dilakukan secara otomatis.

Seperti terjadi pada sistem kontrol temperatur lainya, laju kenaikan temperatur berjalan lebih lambat jka dibandingkan proses flow atau pressue, untuk mengatasi hal ini sistem diberikan overshoot kenaikan temperatur dari batas setpoin untuk mempercepat proses.

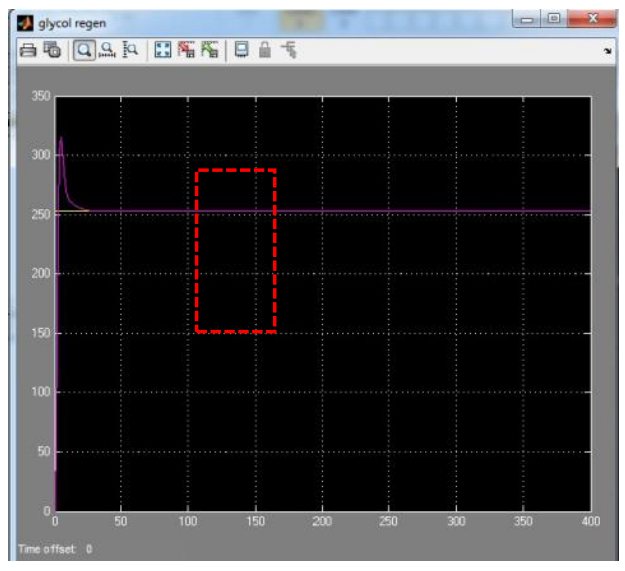

Gambar 11. Grafik output Tuning PID Sistem Kontrol

Selain digunakan untuk keperluan monitoring dan operasioanal, human machine interface (HMI) juga di perlukan untuk pekerjaan engineering [6].

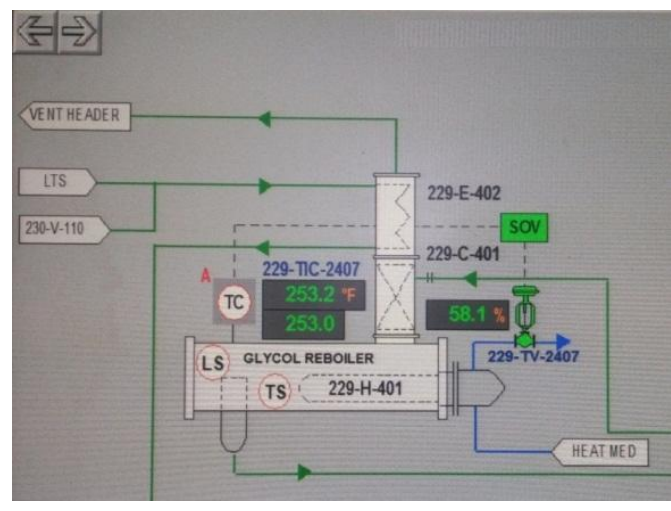

Gambar 12. Human Machine Interface (HMI) Glycol Regeneration

Tampilan HMI pada monitor operator dan engineering secara lengkap menunjukkan kondisi sistem berjalan, dengan tampilan visualisasi plant yang informatif dengan perubahan warna sangat memudahkan untuk monitoring. Proses yang sedang berjalan menunjukkan nilai parameter proses value (PV) $253,2^{0} \mathrm{~F}$ dan setpoin $253^{\circ} \mathrm{F}$, sedangkan kontrol valve pada posisi bukaan $58,1 \%$.

Dari tampilan DeltaV yang terkoneksi dengan field device baik operator maupun enginneer dapat mengamati dan melakukan kegiatan engineering. Parameter-parameter kontroler yang di tambilkan secara real time menampilkan setiap perubahan proses yang terjadi. Sistem ini juga akan menampilkan pesan jika terjadi proses abnormal dari plant maupun perangkat sensing kontroler.

\subsection{Pengujian Sistem Dengan Distrubance}

Dalam operasinya suatu sistem memiliki 3 (tiga) laju produksi yang mungkin terjadi yakni : laju produksi yang tinggi, laju produksi menengah (sesuai nilai operasional perancangan) dan laju produksi yang rendah. Ditinjau dari sudut pengontrolan umpan balik, perubahan laju input rich glycol tersebut pada dasarnya merupakan salah satu bentuk ganguan pada proses pengntrolan.

Untuk mengetahui respon sistem dengan tambahan disturbance ditunjukkan pada gambar 13. Pada kondisi dilapangan, disturbance ini dapat disebabkan oleh aliran dari control valve inlet rich glycol yang secara tiba-tiba 
mendapat masukan berlebih dari kondisi normal, bisa juga di sebabkan kerusakan kontrol valve yang menyebabkan kenaikan suhu glycol regen.

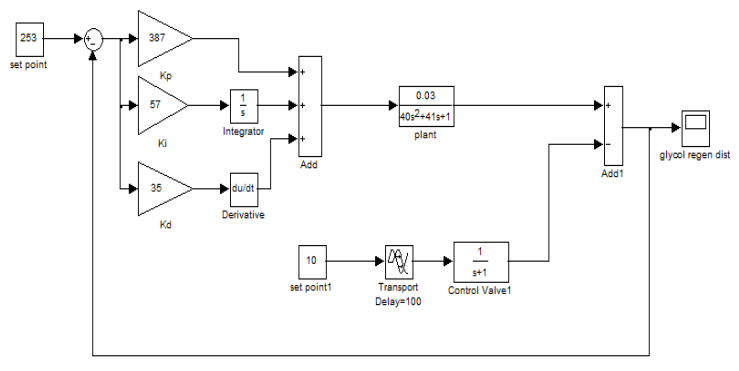

Gambar 13. Blok Simulasi Matlab dengan memberikan gangguan pada sistem

Dengan memberikan asumsi besaran input disturbance akan mengakibatkan perubahan temperatur sebesar $10^{\circ} \mathrm{F}$ kepada sistem yang diasumsikan sebagai input gangguan, didapatkan output scope seperti ditunjukkan pada gambar 14 .

Input gangguan akan dikompensasi oleh sistem sebagai koreksi untuk kestabilan sistem. Dalam hal ini input delay di berikan pada menit ke 100 sebagai pengujian.

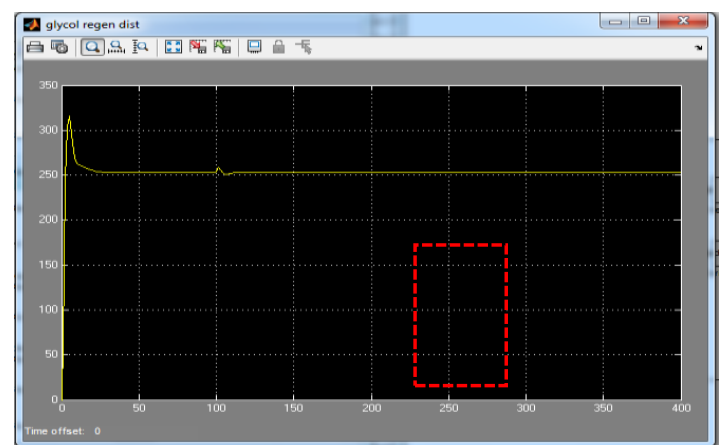

Gambar 14. Grafik gangguan pada sistem delay time 100

\subsection{Sistem Alarm dengan Kondisi Hi- Hi dan Low-Low}

Sistem alarm proses diaktifkan pada kondisi tercapainya nilai-nilai kristis dari parameter proses. Batasan atas dan bawah dari temperatur glycol regen plant dibuat untuk menjaga sistem kontrol dan plant pada nilai parameter kerjanya. Gambar 15 menujukkan reaksi alarm ketika sistem mencapai parameter kritis yang memerlukan tindakan lanjutan secara cepat.

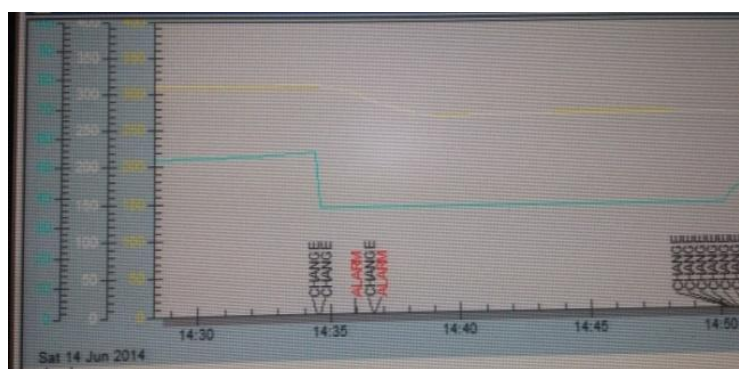

Gambar 15. Sistem Alarm pada Sistem

Alarm pertama diset baik $\mathrm{Hi}$ limit maupun Low limit sebagai pengingat pertama terjadi abnormal pada sistem, sedangkan alarm ke-2 (hi-hi limit da lowlow limit) dapat mengakibatkan keseluruhan glycol regeneration plant shutdown (terhenti operaional).

Tabel 2. Sistem alarm DeltaV

\begin{tabular}{|l|c|c|c|c|}
\hline alarm type & $\begin{array}{c}\text { hi } \\
\text { limit }\end{array}$ & $\begin{array}{c}\text { hi-hi } \\
\text { limit }\end{array}$ & $\begin{array}{c}\text { low } \\
\text { limit }\end{array}$ & $\begin{array}{c}\text { low-low } \\
\text { limit }\end{array}$ \\
\hline $\begin{array}{l}\text { temperatur } \\
\circ \mathrm{F}\end{array}$ & 262 & 290 & 245 & 0 \\
\hline
\end{tabular}

\begin{tabular}{|c|c|c|c|c|}
\hline \multirow{12}{*}{$\begin{array}{l}\text { Limits } \\
\text { Hi Hi Lim } \\
\text { Hi Lim } \\
\text { Dev Hi Lim } \\
\text { Dev Lo Lim } \\
\text { Lo Lim } \\
\text { Lo Lo Lim } \\
\text { Out Hi Lim } \\
\text { Out Lo Lim } \\
\text { ARW Hi Lim } \\
\text { ARW Lo Lim } \\
\text { SP Hi Lim } \\
\text { SP Lo Lim } \\
\text { Alm Hysteresis }\end{array}$} & \multirow{12}{*}{\begin{tabular}{|r|}
290.0 \\
262.0 \\
0.0 \\
0.0 \\
245.0 \\
0.0 \\
100.0 \\
0.0 \\
100.0 \\
0.0 \\
400.0 \\
0.0 \\
0.5
\end{tabular}} & Alarms & Priority & \multirow{2}{*}{ Enab Supp } \\
\hline & & $\mathrm{HI} \mathrm{HI}$ & CRIIICAL & \\
\hline & & $\mathrm{Hi}$ & WARNING & $\checkmark \square$ \\
\hline & & Dev Hi & ADVISORY & 00 \\
\hline & & Dev Lo & ADVISORY & 00 \\
\hline & & Lo & WARNING & $\checkmark$ \\
\hline & & Lo Lo & CRIIICAL & $\checkmark \square$ \\
\hline & & PV Bad & CRITICAL & $\checkmark$ \\
\hline & & Priority Adj & $0 \quad-1$ & \\
\hline & & Diagnostics & & \\
\hline & & MERROR |MSTATUS ] & | BLOCK_ERR | & \\
\hline & & Module OK & & \\
\hline Simulate & & & & \\
\hline Sim Enable & & & & \\
\hline $\begin{array}{l}\text { Sim Value } \\
\text { Field Value }\end{array}$ & \begin{tabular}{|l|}
63.3 \\
$63.3 \%$ \\
\end{tabular} & & & \\
\hline
\end{tabular}

Gambar 4.8 Setting Alarm Low dan Hi Limit

Timbulnya alarm merupakan respon dari terjadinya ganguan (disturbance) pada sistem. Perubahan radikal pada sistem yang memicu alarm biasa disebabkan dari input rich glycol yang meningkat secara tiba-tiba, hal ini mengakibatkan temperatur plant turun. Faktor kedua disebabkan oleh kerusakan heat medium yang menyebabkan tidak dapat memberikan panas sesuai kebutuhan.

Langkah yang dapat diambil operator monitoring dengan melaporkan kondisi kerusakan ke engineering dan maintenance team, team yang melakukan perbaikan nantinya akan mensimulasi 
glycon regeneration secara manual sampai perbaikan selesai. Tindakan ini diambil agar sistem lain yang saling terkait dengan DeltaV tidak melakukan proses shutdown seluruh plant secara otomatis.

\section{KESIMPULAN}

1. Dengan menggunakan metode osilaso dengan sistem loop tertutup diperoleh hasil tuning PID dengan parameter $P=387, l=57$ dan $D=53$.

2. Respons sistem control dikondisikan overshoot dari setpoinnya untuk mempercepat kenaikan temperatur plant.

3. Pada saat temperature glycol regeneration berada pada titik kerja $262^{\circ} \mathrm{F}$ alarm akan menyala $\mathrm{Hi}$ limit dan $\mathrm{Hi} \mathrm{Hi} \mathrm{limit} \mathrm{pada} \mathrm{temperatur} 290^{\circ} \mathrm{F}$, sedangkan pada temperatur $245^{\circ} \mathrm{F}$ akan menyala Low limit dan Low Low limit pada temperatur $0^{\circ} \mathrm{F}$

\section{REFERENSI}

[1] T. Katz, G. Sieder, and J. Hearn. 2013. "The effect of glycols on the performance of the acid gas removal process," IGT Int. Liq. Nat. Gas Conf. Proc., vol. 3, pp. 1-16.

[2] K. Kolmetz. 2012. "Gas Dehydration (ENGINEERING DESIGN GUIDELINE )".

[3] H. S. N. Muzwar, A. K.2014. Pamososuryo, and E. Ekawati, "Pemodelan Kolom Distilasi Pabrik Petrokimia dengan Menggunakan Distributed Control System," J.Oto.Ktrl.Inst, vol. 6, no. 2, pp. 8594.

[4] N. Jafar, M. T. A. Ichsan, and S. Widodo. 2016. "Analisis Glycol Pada Proses Dehydration Gas Stasiun G-8 Aset Tarakan Proppinsi Kalimantan Utara," J. Geomini, vol. 4, no. 2, pp. 76-79.

[5] I. Setiawan. 2008. Kontrol PID Untuk Proses Industri.

[6] T. Article. 2010. "Design Considerations for Effective Human Machine Interface Systems". 